\title{
Digital Humanitarianism
}

Digital humanitarianism is humanitarian intervention conducted at a distance, sometimes without physical presence on the ground, through digital tools and often in an online, collaborative manner including citizen participation. It is technically a consequence of the rapid spread of mobile phones, internet connectivity, social media, and geographical information systems that enable a large number of individuals to effectively collaborate online. When a major crisis occurs, affected populations and concerned organizations turn to their mobile phones or to the internet to seek and to share information on the crisis. Digital humanitarianism developed as a way to describe the activity of volunteers and organizations who apply digital tools to capture this flow of online information, organize it, locate it, and verify its content. The collection and mapping of social media messages after the Haiti earthquake in 2010 is claimed to be the birth of digital humanitarian activity (Meier 2015). Countless humanitarian interventions by ad hoc groups of volunteers or by established organizations have been facilitated by the fact that affected populations are able to share information globally in real time, and concerned citizens are able to organize and act online. Open geographical information systems have made it possible to organize, visualize, and share such information, and the humanitarian community has adopted the value of information sharing both as a supportive activity and as a humanitarian activity on its own (Burns 2014; Harvard Humanitarian Initiative 2011).

In the early days of digital humanitarianism, activities were closely connected to tools such as OpenStreetMap (OSM), Ushahidi, or Sahana. osm is the "Wikipedia of maps": an online community of volunteers digitally draws maps, including areas where no maps are currently available. The maps are created using available satellite imagery alongside the community on the ground, which provides place names and details to enrich the map. Similarly, Ushahidi is a platform created for online collaboration to visualize information from sMs text messaging or social media messages by verifying, categorizing, and locating the information on a map. The Sahana platform was developed in a similar setting to allow for online information sharing and collaboration among a large group of users (Burns and Shanley 2012). A growing technical community and private companies engaging in humanitarian crises have led to ever new technologies being applied for humanitarian purposes.

The transition from in-kind to cash-based aid using digital devices and the introduction of biometric ID shas led to the adaption of digital humanitarianism to cover such activities. Drawing the line between humanitarian technology 
and digital humanitarianism is a subject of dispute. The rapid increase in connectivity and commercial interest in connecting the world and the subsequent digitalization of education, relief, and humanitarian services, are exposed to critical reflection. Connectivity and open sharing of information generate security risks because it is not always possible to monitor those using the online information and for what purpose (Sandvik, Gabrielsen Jumbert, Karlsrud and Kaufmann 2014). Others claim that digital humanitarianism, remote management, and distant sensing help "to occlude the negative by headlining the problem-solving potential of technoscience" (Duffield 2016: 154). As technooptimists promote the new digital reality, others challenge the humanitarian adaptation of digital tools, and see them as a threat to true relief or development and as tools for surveillance and oppression (Duffield 2016). In between, there is a broad horizon for exploring the effects, risks, and possibilities of new technologies adapted to a humanitarian landscape.

\section{Per Aarvik}

\section{References}

Burns, R. (2014) Moments of Closure in the Knowledge Politics of Digital Humanitarianism. Geoforum, 53: 51-62.

Burns, R., Shanley, L. (2012) Connecting Grassroots to Government for Disaster Management. Woodrow Wilson Center Research Series.

Duffield, M. (2016) The Resilience of the Ruins: Towards a Critique of Digital Humanitarianism. Resilience, 4(3): 147-165.

Harvard Humanitarian Initiative (2011) Disaster Relief 2.o: The Future of Information Sharing in Humanitarian Emergencies. https://hhi.harvard.edu.

Meier, P. (2015) Digital Humanitarians. Routledge.

Sandvik, K.B., Gabrielsen Jumbert, M., Karlsrud, J., Kaufmann, M. (2014) Humanitarian Technology: A Critical Research Agenda. International Review of the Red Cross, 96(893): 219-242.

\section{Diplomacy}

Providing ongoing access to humanitarian aid during conflict and complex emergencies has always been a major concern for policy-makers and 